\title{
Original
}

\section{Catecholaminergic Innervation of LHRH Neurons in the Rat Medial Preoptic Area Analyzed by Electron Microscopy and Double Immunolabeling}

\author{
Koji Samejima and Yasumitsu NaKaI
}

\begin{abstract}
We used electron microscopy to examine the catecholaminergic innervation of neurons containing luteinizing hormone releasing hormone (LHRH) in the medial preoptic area of the rat. Double immunolabeling was used with the antisera of LHRH and tyrosine hydroxylase (TH) or phenylethanolamine-N-methyltransferase (PNMT), which are biosynthetic catecholamine enzymes. In simple LHRH-immunolabeled sections, immunonegative terminals making synaptic contacts with LHRH-like immunoreactive (LHRH-LI) nerve cell bodies and processes were sometimes found. In double immunolabeled sections, catecholaminergic axon terminals labeled with $\mathrm{TH}$ were found making synapses with LHRH-LI nerve cell bodies and processes. PNMT immunoreactive terminals, but fewer than TH-immunoreactive terminals, were also found making axo-somatic and probably axo-dendritic synapses with LHRH-LI neurons. LHRH-LI terminals were occasionally found making synapse-like contacts with LHRH-LI cell bodies or processes. It thus appears that in the medial preoptic area of the rat, catecholaminergic neurons, at least those containing adrenaline, innervate neurons containing LHRH and regulate their secretory activity or other functions through synapses.
\end{abstract}

Key words: catecholaminergic innervation, LHRH neurons, medial preoptic area, rat

\section{Introduction}

Catecholamines are involved in the control of gonadotropin secretion. In vitro physiological and pharmacological studies have shown that dopamine ${ }^{1)}$ and noradrenaline ${ }^{2,3)}$ stimulate LHRH release at the median eminence level and in the medial preoptic area. Adrenaline is important in neuronal control of preovulatory gonadotropin surge ${ }^{4)}$, and it acts as a central depressant or a central excitant depending on dose and mode of administration ${ }^{5)}$. These differences in the effects of adrenaline reflect the complexity and sensitivity of the system involved in the regulation of LHRH secretion.

Light microscopy combined with histofluorescence and immunocytochemistry ${ }^{(6) 8)}$ or doublelabel immunocytochemistry ${ }^{9-12)}$ have shown interactions between catecholaminergic neurons and LHRH-containing neurons in the rat hypothalamus. Lehman et al. ${ }^{13)}$ using double label immunohistochemistry, reported that varicosities that are immunoreactive to tyrosine hydro-

Department of Anatomy, Showa University School of Medicine, 1-5-8 Hatanodai, Shinagawa-ku, Tokyo 142, Japan. 
xylase (TH)- or dopamine- $\beta$-hydroxylase $(\mathrm{DBH})$ appear to contact LHRH immunoreactive neurons in the preoptic area and anterior hypothalamus of sheep.

Watanabe and Nakai ${ }^{14)}$, using electron microscopy, reported that 5-hydroxydopamine (5OHDA)-, ${ }^{3} \mathrm{H}$-dopamine- or ${ }^{3} \mathrm{H}$-noradrenaline-labeled terminals of catecholaminergic neurons synapse with LHRH-like immunoreactive (LHRH-LI) nerve cell bodies and fibers in the medial preoptic area of the rat. They used 5-OHDA labeling or autoradiography combined with immunocytochemistry. Recently, Leranth et al. ${ }^{15)}$ demonstrated direct synaptic connections between TH axons and LHRH neurons in the rat medial preoptic area. They used a double-label, immunostaining technique with avidine-biotin-peroxidase and avidinated gold.

However, although nerve fibers and terminals containing adrenaline were heretofore reported to be distributed in the rat medial preoptic area and the mediobasal hypothalamus ${ }^{16)}$, adrenergic innervation of LHRH neurons there had not been demonstrated morphologically. The present study was aimed at examining synaptic relations between adrenergic terminals containing PNMT and LHRH neurons, and determining the distribution ratio of presynaptic terminals containing $\mathrm{TH}$, the first enzyme in the catecholamine synthesis pathway, and PNMT, the final enzyme in conversion from noradrenaline to adrenaline in the pathway. To do this, we used a preembedding, double immunolabeling technique based on the consecutive use of silver-gold intensified (SGI) peroxidase-antiperoxidase complex (PAP)-3,3'diaminobenzidine (DAB) method using LHRH antiserum, and the PAP-DAB method with PNMT and TH antisera.

\section{Materials and Methods}

Animals

Twenty-four adult male Wistar rats (150-200 g) were used. All animals were injected in the lateral ventricle with colchicine $(80 \mu \mathrm{g} / 100 \mathrm{~g}$ b.w. dissolved in $5 \mu \mathrm{l}$ saline) under nembutal anesthesia $(40 \mathrm{mg} / \mathrm{kg}$; i.p.) $36 \mathrm{~h}$ before sacrifice.

Fixation

The animals, re-anesthetized with nembutal, were sacrificed by perfusion through the ascending aorta with $80-150 \mathrm{ml}$ of $0.1 \mathrm{M}$ phosphate buffered saline (PBS, $\mathrm{pH} 7.4$ ) followed by a $4 \%$ solution of paraformaldehyde (PFA) buffered at $\mathrm{pH} 6.5-10.8$. The preoptic areas were excised out and immersed in high-pH solution overnight at $4{ }^{\circ} \mathrm{C}$, then sectioned at $30-$ $40 \mu \mathrm{m}$ on a vibratome (Oxford Instrument, U.S.A.).

Immunocytochemical labeling

After being rinsed in PBS, the selected vibratome sections were placed in $2 \%$ normal goat serum-PBS solution and divided into two subgroups for immunocytochemical staining in different sequences. One subgroup was immunostained first for LHRH by the traditional PAPDAB methods, and then for TH or PNMT by the silver gold intensified (SGI)-PAP-DAB method. The other was immunostained first for TH or PNMT by the PAP-DAB method, and then for LHRH by the SGI-PAP-DAB method. Anti-LHRH, anti-TH, and anti-PNMT antisera were used in dilutions of $1: 4000,1: 2000$ and 1:4000, respectively. The sections were kept in the primary antibodies for $36-48 \mathrm{~h}$ and for $1-1.5 \mathrm{~h}$ in each of the bridging antibodies: goat-anti-rabbit IgG (1:100) and PAP-complex (1:100). After being rinsed in PBS, the sections were incubated for 5-10 min in low-pH substrate solution ( $\mathrm{pH} \mathrm{5.1)}$ containing p-cresol.

Silver-gold intensification of DAB chromogen 
Briefly, the three main steps were: a) The sections were incubated for $2 \mathrm{~h}$ in $10 \%$ thioglycolic acid diluted in distilled water to suppress the argyrophil III reaction of the nervous tissue. b) Physical developing: After being rinsed in a $2 \%$ sodium acetate solution for $2 \mathrm{~h}$, the $\mathrm{DAB}$ end product was intensified with physical developer, then transferred to a $1 \%$ acetic acid solution to terminate the reaction. c) Gold toning: After a rinse in $2 \%$ sodium acetate, the sections were put into a $0.05 \%$ gold chloride solution at $4{ }^{\circ} \mathrm{C}$ for $10 \mathrm{~min}$. Immunohistological detection of a second antigen by the PAP-DAB method

After keeping the sections in $2 \%$ normal goat serum-PBS solution for $10 \mathrm{~min}$, the intensified sections were kept over night at $4^{\circ} \mathrm{C}$ in the primary antibody anti-TH, anti-PNMT or anti-LHRH antiserum containing PBS plus $1 \%$ normal goat serum to detect the second tissue antigen. These structures were visualized by the PAP method, using the DAB chromogen alone as described above.

As a control, the tissue sections were incubated with LHRH antiserum preabsorbed with synthetic LHRH $(25 \mu \mathrm{g} / \mathrm{ml}$ diluted LHRH antiserum) or TH $(20 \mu \mathrm{g} / \mathrm{ml}$ diluted TH antiserum) or PNMT $(25 \mu \mathrm{g} / \mathrm{ml}$ diluted PNMT antiserum) for $24 \mathrm{~h}$.

After incubation, all tissue sections were postfixed in $1 \% \mathrm{OsO}_{4}$ in $0.1 \mathrm{M}$ phosphate buffer ( $\mathrm{pH}$ 7.4) for $1 \mathrm{~h}$ at $4{ }^{\circ} \mathrm{C}$, dehydrated in a graded ethanol series and embedded in a mixture of Epon-Araldite. Ultrathin sections cut on an LKB ultratome and a Porter Blum microtome were stained wtih uranyl acetate and lead citrate. The ultrathin sections were examined at 75 and $100 \mathrm{KV}$ with Hitachi HS-9 and $\mathrm{H}-800$ electron microscopes.

In the double immunostaining sections, the densities of $\mathrm{TH}$-immunoreactive terminals making synaptic contact with LHRH-LI neurons were compared with PNMT-immunoreactive terminals making such contacts.

\section{Results}

Light microscopy: In the sections double immunostained by combining the SGI-PAP$\mathrm{DAB}$ and PAP-DAB methods, the SGI-DAB chromogen appeared as black to silver-gold

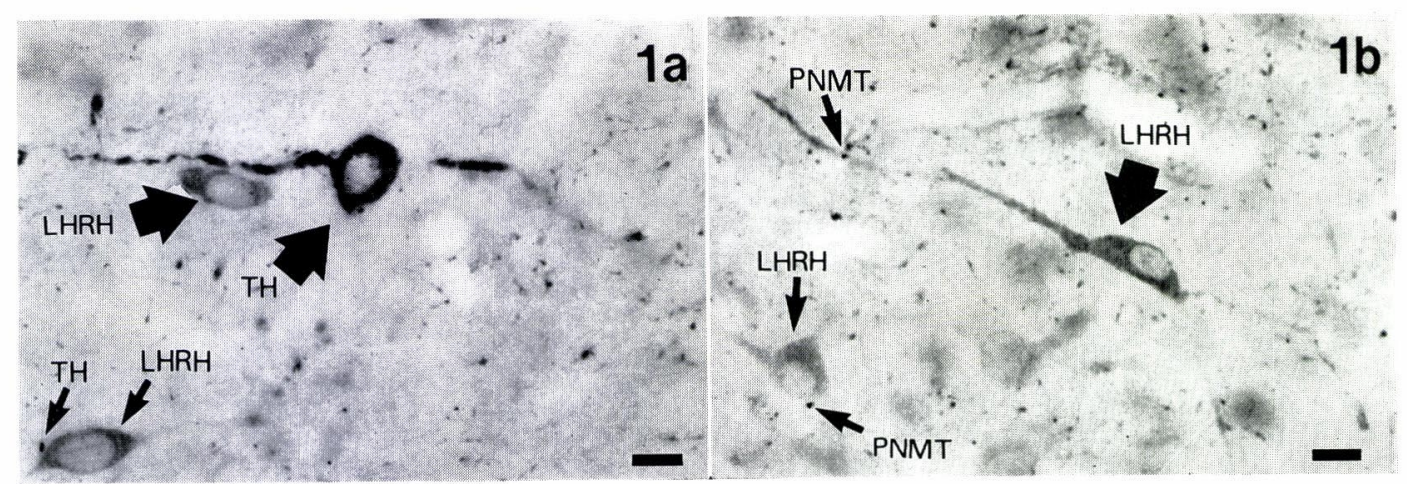

Fig. 1. Light microscope results of immunohistological double labeling using SGI-PAP-DAB labeling of neurons containing TH and PNMT, and non-SGI-PAP-DAB chromogen labeling of neurons containing LHRH in the preoptic area. Note the distinct colors of the different immunolabels. a: Light micrograph showing black TH-LI nerve cell bodies and varicose fibers in the vicinity of gray LHRH-LI neurons. A bar indicates $10 \mu \mathrm{m}$. b: Light micrograph showing PNMT-LI varicosities and LHRH-LI nerve cell bodies occuring together. A bar indicates $10 \mu \mathrm{m}$. 
particles. They were easily distinguished from the non-intensified, brown DAB-only end product. LHRH-LI nerve cell bodies were most numerous in the medial preoptic area adjacent to the organum vasculosum of the lamina terminalis. LHRH-LI fibers with beaded varicosities were widely distributed throughout the preoptic area. Catecholaminergic TH-LI nerve cell bodies and fibers, as well as PNMT-LI nerve fibers, were found in the medial preoptic area. Occasionally, varicose TH- or PNMT-LI fibers and their terminals appeared in contact with both LHRH-LI cell bodies and processes (Fig. 1a, b).

Omission of a selected individual primary antiserum from the combined immunolabeling procedure eliminated the labeling corresponding to that particular antigen.

Electron microscopy: In the LHRH single-immunolabeled sections immunostained by the

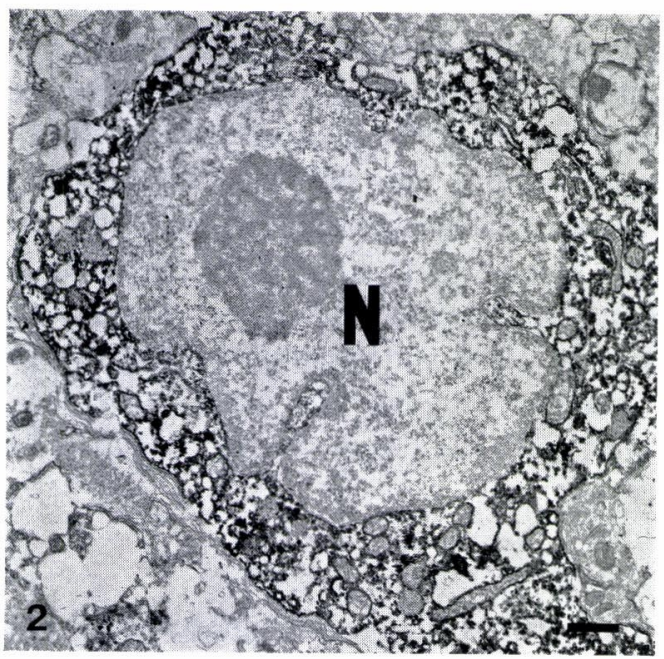

Fig. 2. Ultrastructure of silver-gold intensified LHRH-LI cell body in the medial preoptic area of the rat. Note the intense electron density of the silver-gold intensified chromogen. $\mathrm{N}$ : nucleus. A bar indicates $1 \mu \mathrm{m}$.
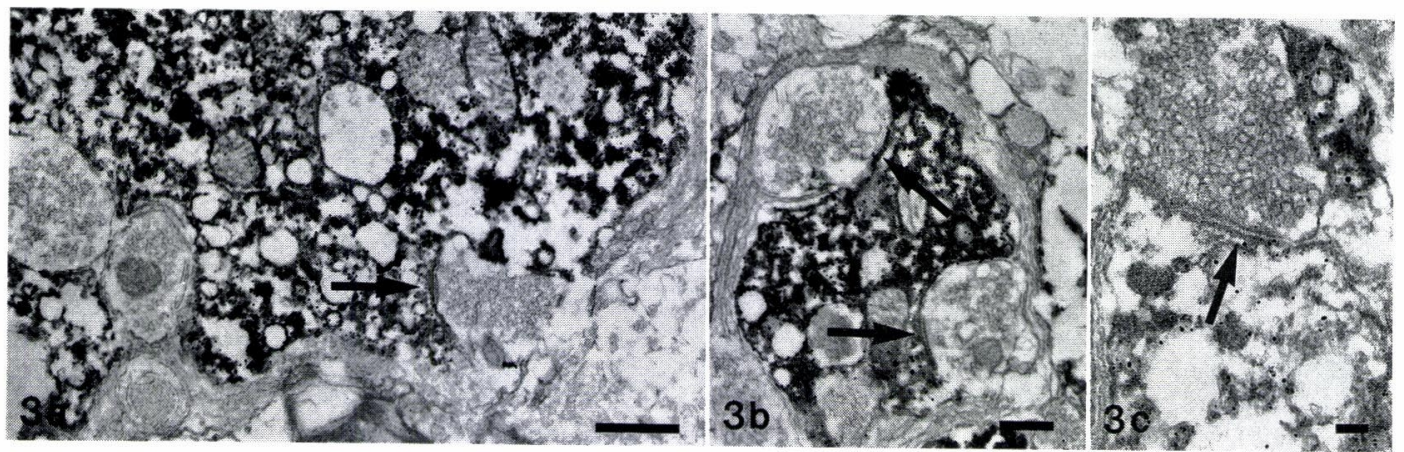

Fig. 3. a: Three immunonegative axon terminals making contact with a silver-gold intensified LHRH-LI perikaryon. One terminal is in synaptic contact (arrow). A bar indicates $1 \mu \mathrm{m}$. b: Two immunonegative terminals making synapse-like contract (arrow) with an LHRH-LI cell process. A bar indicates $5 \mu \mathrm{m}$. c: An immunonegative axon terminal make synaptic contact (arrow) with an LHRH-LI cell process. A bar indicates $5 \mu \mathrm{m}$. 
SGI-PAP-DAB method, the silver-gold postintensification of the DAB chromogen significantly increased the electron density of the immunolabeled profiles (Fig. 2). The diameters of individual metal grains were $8-10 \mathrm{~nm}$. LHRH-like immunoreactivity appeared in the secretory granules (80-130 nm in diameter) and on the surfaces of mitochondria, on rough endoplasmic reticulum, and throughout the cytoplasmic matrix. The immunonegative axon terminals often made axo-somatic (Fig. 3a) and axo-dendritic and/or axo-axonic synapses (Fig. $3 b$, c) with the LHRH-LI nerve cell bodies and processes. Their synaptic types were not so clearly differentiated as either the asymmetrical Gray I types or the symmetrical Gray II types.

LHRH neurons received multiple synaptic inputs on their cell body surfaces and there were few processes. Synaptic inputs onto LHRH-LI cell processes occurred much more frequently than those onto cell bodies.

LHRH-LI terminals making synapse-like contacts with LHRH-LI cell bodies or processes were rarely found in the medial preoptic area (Figs. 4, 7).

In the double immunolabeled sections, both TH-LI (Figs. 5-7) and PNMT-LI (Figs. 9, 10) axon terminals were sometimes found to synapse with LHRH-LI nerve cell bodies and processes in the medial preoptic area. Occasionally both TH-LI and immunonegative terminals in close apposition synapsed with the same LHRH nerve cell bodies and processes (Fig. 5b). TH-labeled presynaptic terminals contained both numerous immunonegative small clear vesicles and a few relatively large immunoreactive granular vesicles (Figs. 5-7), and PNMT-LI presynaptic terminals also contained a few immunoreactive granular vesicles be-

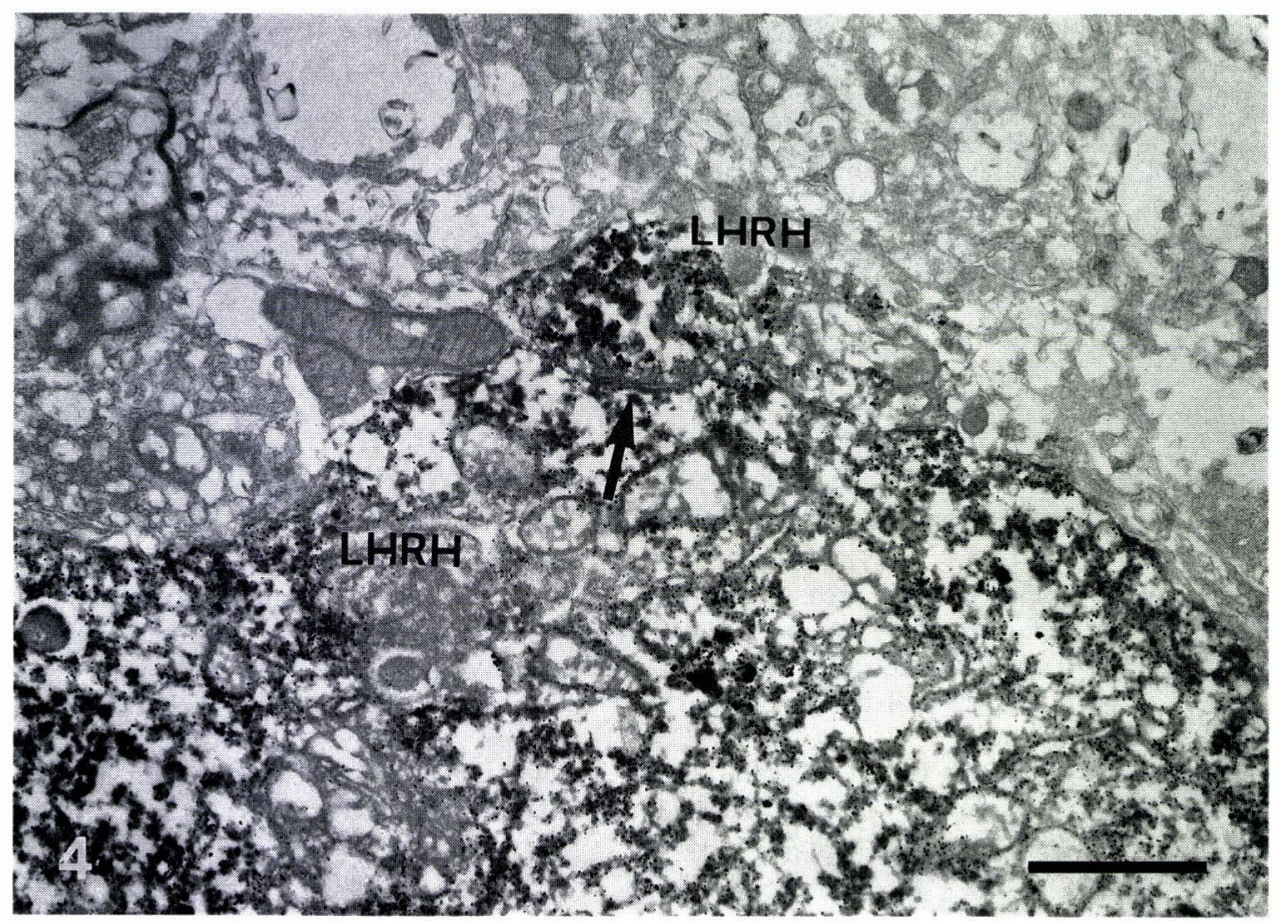

Fig. 4. Evidence for LHRH-LHRH interactions. An LHRH-LI terminal with silver-gold intensified chromogen is shown making a synapse (arrow) with another intensified LHRH-LI cell body. A bar indicates $1 \mu \mathrm{m}$. 


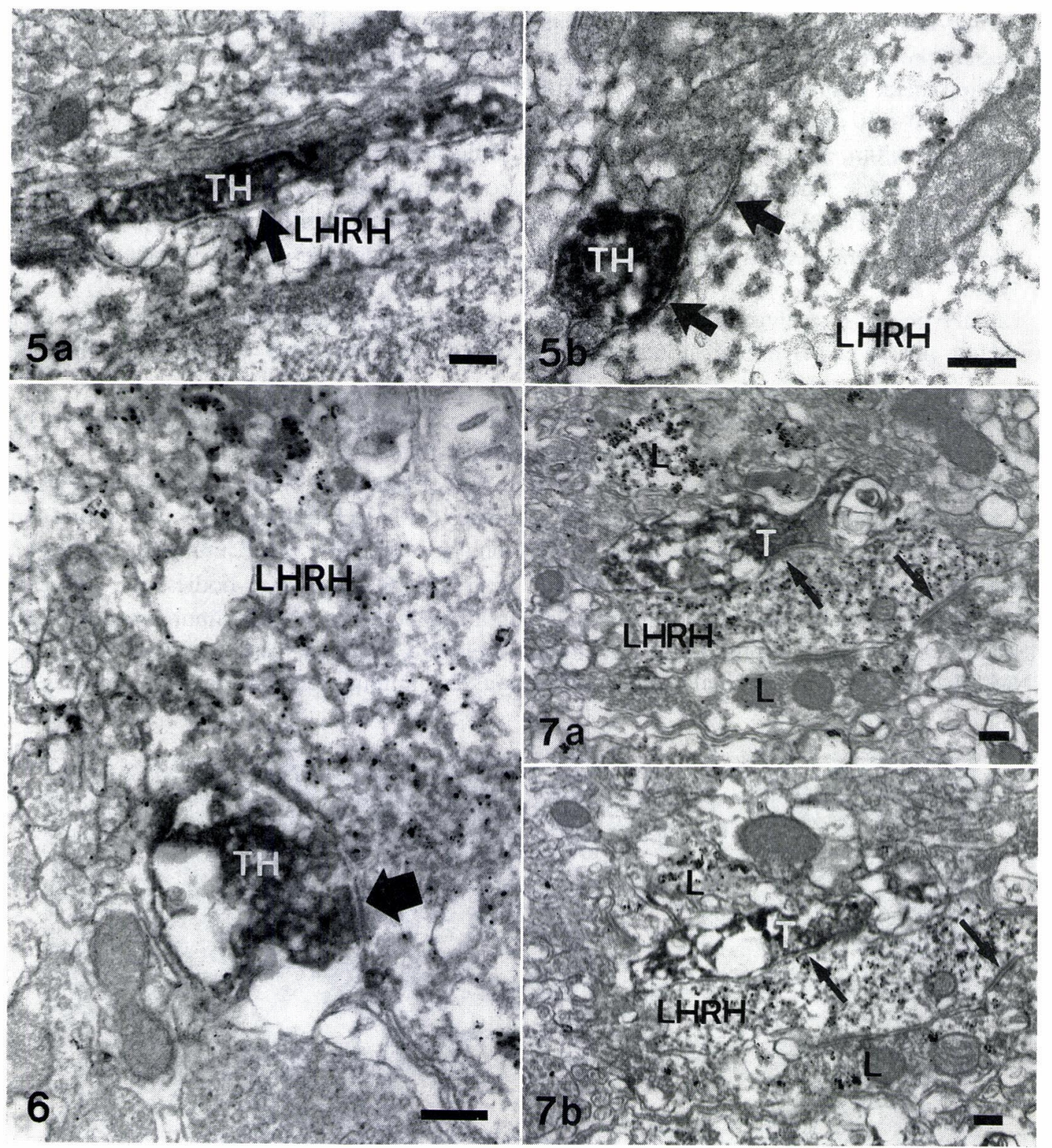

Fig. 5. a: A TH-LI process closely contacts (arrow) LHRH-immunoreactive perikaryon in the medial preoptic area. A bar indicates $5 \mu \mathrm{m}$. b: TH-LI terminal in parallel with an immunonegative terminal similarly making synaptic contact (arrows) with an LHRH-like immunoreactive process. A bar indicates $5 \mu \mathrm{m}$.

Fig. 6. A TH-LI terminal in synapsis (arrow) with an LHRH-LI process. A bar indicates $5 \mu \mathrm{m}$.

Fig. 7. Serial sections (a, b) of both TH-LI (T) and LHRH-LI (L) terminals in synaptic contact (arrows) with an LHRH-LI (LHRH) process. A bar indicates $5 \mu \mathrm{m}$. 


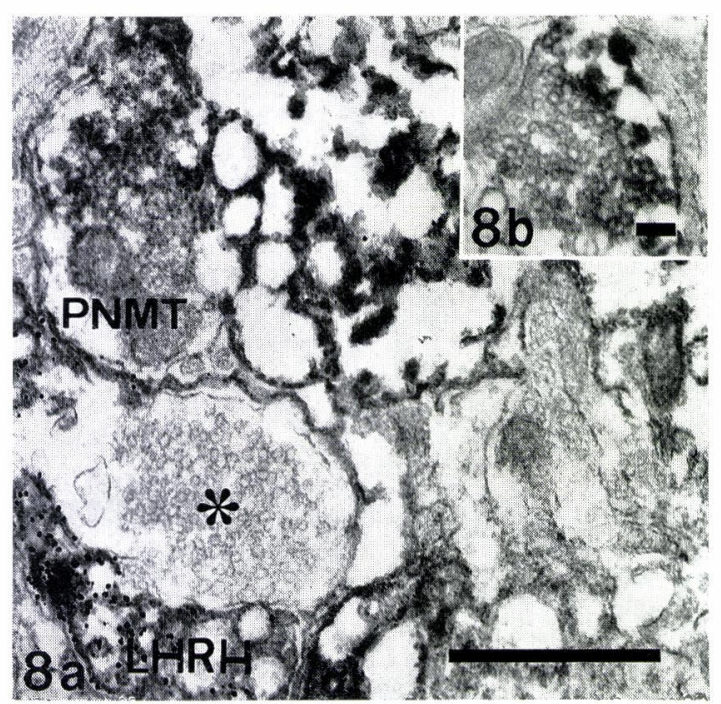

Fig. 8. a: A PNMT-LI terminal labeled with DAB chromogens, an LHRH-LI process intensified with silver-gold intensified chromogen, and an immunonegative axon terminal (*) in the medial preoptic area. A bar indicates $1 \mu \mathrm{m}$. b: PNMT-LI axon terminals containing a few large immunoreactive dense granules and numerous small immunonegative clear synaptic vesicles. A bar indicates $5 \mu \mathrm{m}$.

Table 1. The density of TH-LI and PNMT-LI terminals with synapses onto the LHRH-LI perikarya and processes.

\begin{tabular}{lcc}
\hline \multicolumn{1}{c}{ Synapse } & Profile & Positive $(\%)$ \\
\hline LHRH-TH & 142 & $12(8.3 \%)$ \\
LHRH-PNMT & 250 & $4(1.6 \%)$ \\
\hline
\end{tabular}

sides numerous immunonegative small clear vesicles (Figs. 8-10).

We compared the densities of synaptic inputs of TH-LI or PNMT-LI terminals on the LHRH-LI neurons in the double immunolabeled sections of the medial preoptic area. The density of TH-LI terminals making synaptic inputs into the LHRH-LI neurons was about $8.3 \%$ and that of PNMT-LI terminals was about $1.6 \%$ of all the axon terminals making synapses on the LHRH-LI neurons (Table 1). In both cases, axo-dendritic and/or axoaxonic synapses onto LHRH-LI neurons were much denser than axo-somatic synapses.

\section{Discussion}

Our data on the localization of LHRH immunoreactive neurons in the rat brain agree well with earlier studies ${ }^{\tau, 9,11,12)}$. Most LHRH neurons are in the medial preoptic area and the diagonal band of Broca.

Using a different technique from Leranth et al. ${ }^{15)}$, we again proved synaptic inputs between TH- and LHRH-containing neurons in the preoptic area. This is also supported by a previous light microscope, immunohistochemical demonstration of direct contacts between dopamine-containing and LHRH-containing terminals in the rat hypothalamus without intervening glial elements ${ }^{17)}$. Leranth et al. ${ }^{15)}$ reported that most of the synapses between $\mathrm{TH}$ 


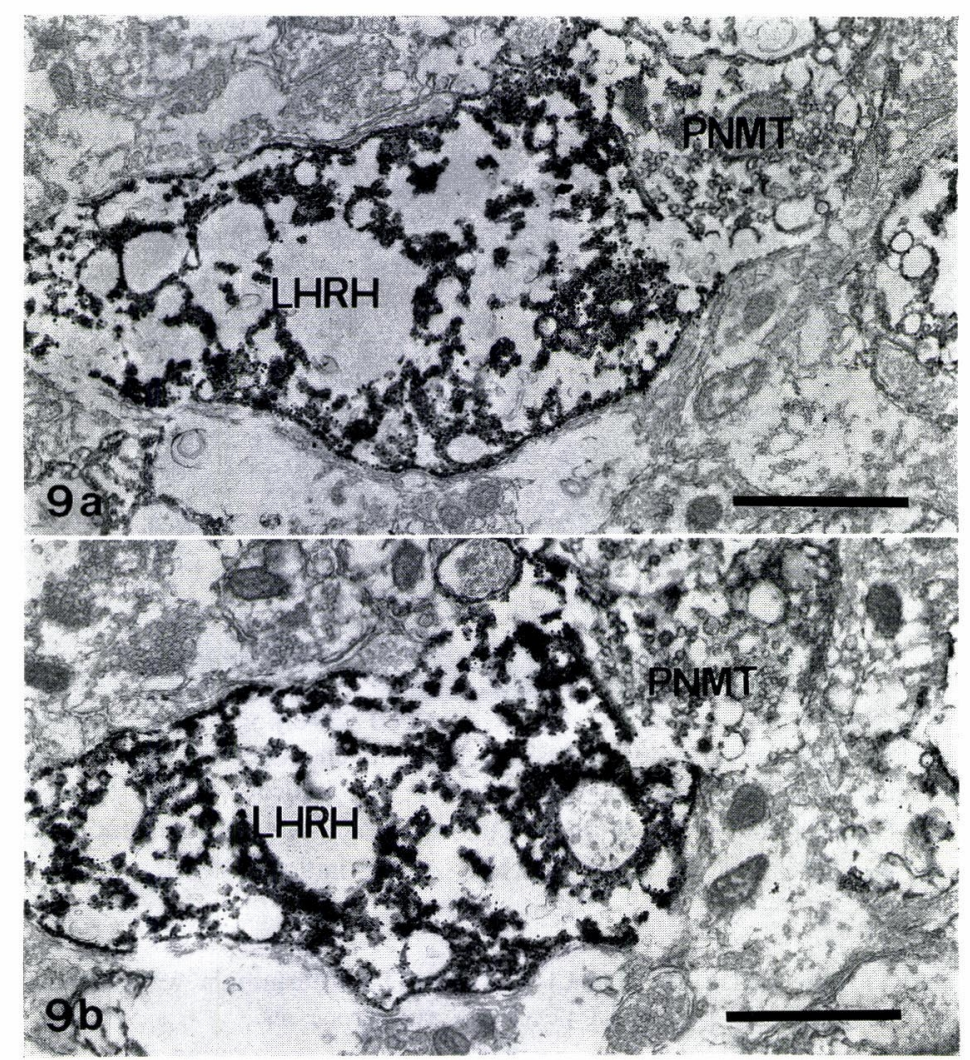

Fig. 9. Serial sections (a, b) of a PNMT-LI terminal synapsing (arrow) with an LHRH-like immunoreactive process. A bar indicates $1 \mu \mathrm{m}$.

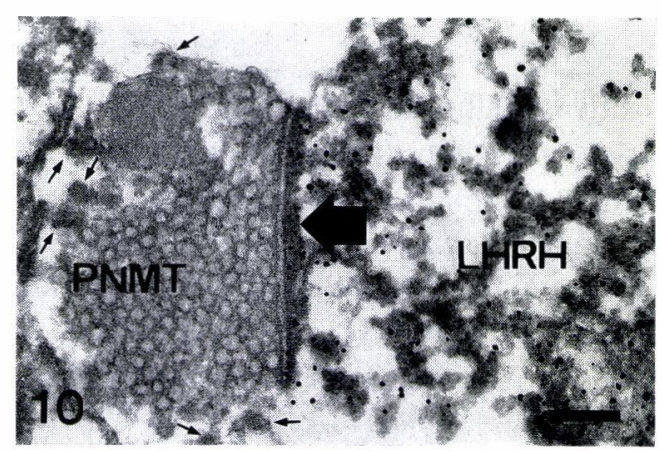

Fig. 10. High power electron microphotograph shows a terminal with PNMT-LI granular vesicles (PNMT) (arrows) establishing asymmetric synaptic contact (arrow) with an LHRH-LI (LHRH) cell body. A bar indicates $5 \mu \mathrm{m}$.

boutons and LHRH neurons appeared to be symmetric, but we could not clearly verify this.

Since Kiss and Halász ${ }^{18)}$ demonstrated synaptic contacts between ${ }^{3} \mathrm{H}$-5-hydroxytryptamine (5-HT)-labeled terminals and LHRH-immunoreactive dendrites in the rat medial preoptic area, using combined immunocytochemistry and high resolution autoradiography, some evidence of synaptic inputs, such as dopamine ${ }^{14)}$, noradrenaline ${ }^{14)}, \gamma$-amino-butyric-acid ${ }^{19)}$, pro- 
opiomelanocortin $^{20)}, \beta$-endorphin ${ }^{21)}$, and neuropeptide $\mathrm{Y}^{22)}$, upon LHRH-immunoreactive perikarya or processes have been demonstrated by double-label immunocytochemistry.

This is the first morphological determination of adrenergic innervation of LHRH-containing neurons demonstrated by PNMT-LI terminals synapsing with LHRH-immunoreactive neurons. This was ultrastructural verification of previous light microscopic ${ }^{16)}$ and physiological ${ }^{4)}$ findings that suggested adrenergic innervation of LHRH neurons. From the density of THLI and PNMT-LI terminals synapsing on LHRH neurons (Table 1), the ratio of innervation of LHRH neurons by adrenergic neurons is considered to be less than that by other catecholaminergic neurons. Jennes et al. ${ }^{11)}$ demonstrated by light microscopy and double immunostaining that DBH immunoreactive fibers in adult rats are in apposition to LHRH-producing cells in the septo-preoptic area. They suggested that noradrenergic or adrenergic fibers, rather than dopaminergic fibers, probably interact directly with LHRH neurons. We could not get good immunolabeling of DBH-containing neurons in the medial preoptic region, although DBH immunoreactive cell bodies and fibers were found in the periventricular nucleus and the arcuate nucleus. This may be a technical problem. Wray and Hoffman ${ }^{23)}$ reported that most brain regions containing LHRH cell bodies contained noradrenergic rather than adrenergic fibers, but the possibility that adrenergic afferents might provide some input to the LHRH neurons cannot be ruled out.

It has been suggested, after combined retrograde tract tracing with histofluorescence, that the A1 (lateral reticular nucleus in the medulla oblongata) and A2 (inside and around the nucleus of the solitary tract) noradrenergic groups in the medulla are the major sources of catecholamine fibers in the preoptic area that might synapse on LHRH-containing neurons in the rat hypothalamus, although a possible contribution from dopaminergic cells in the periventricular region of the hypothalamus (A14 group of Dahlstrom and Fuxe) can not be excluded ${ }^{24)}$. In addition, the medullary adrenergic neurons that partly overlap the $A 1$ and A2 noradrenergic cell groups ${ }^{25}$ and our present finding of direct contacts between adrenaline- and the LHRH-containing terminals, suggest that the $\mathrm{C} 1$ (ventro-lateral), C2 (medio-dorsal portion of the medulla) and C3 (medial longitudinal fasciculus) adrenergic cell groups may also be origins.

Direct contacts between the same LHRH immunoreactive neurons have been demonstrated in the rat, guinea pig, human and monkey brain ${ }^{11,20,26)}$ by immunocytochemical observations using both light and electron microscopy. In the present study, close contact of LHRH perikarya was observed in the preoptic region. This morphology may indicate basis for a special ultra-short feedback circuit whereby LHRH directly influences the secretory activity of LHRH neurons or synchronizes the excitation of several LHRH neurons to accelerate LHRH release. This possibility is supported by experiments performed in vivo and in vitro models which showed that intraventricular administration of small doses of LHRH paradoxically decreased serum $\mathrm{LH}$ and the frequency of $\mathrm{LH}$ pulses in ovariectomized female rats as well as preovulatory $\mathrm{LH}$ release $^{2 i}$ ).

In conclusion, our present findings indicate that in the medial preoptic area of the rat, catecholaminergic neurons, at least those containing adrenaline, innervate neurons containing LHRH to regulate their secretory activity or other functional activity through synapses.

\section{References}

1) Bennett GW, Edwardson JA, Holland D, Jeffcoate SL and White N: Release of immunoreactive 
luteinizing hormone-releasing hormone and thyrotropin-releasing hormone from hypothalamic synaptosomes. Nature, 257: 323-325 (1975)

2) Negro-Vilar A, Ojeda SR and McCann SM: Catecholaminergic modulation of luteinizing hormonereleasing hormone released by median eminence terminals in vitro. Endocrinology, 104: 1749-1757 (1979)

3) Heaulme M and Dray F: Noradrenaline and prostaglandin E2 stimulate LH-RH release from rat median eminence through distinct 1-alpha-adrenergic and PGE2 receptors. Neuroendocrinology, 39: 403-407 (1984)

4) Coen CW and Coombs MC: Effects of manipulating catecholamines on the incidence of the preovulatory surge of luteinizing hormone and ovulation in the rat: Evidence for a necessary involvement of hypothalamic adrenaline in the normal or "midnight" surge. Neuroscience, 10: 187-206 (1983)

5) Marley E and Stephenson JD: Central actions of catecholamines. In: Catecholamines, Blaschko $\mathrm{H}$ and Muscholl E (Eds), Springer, Berlin, pp 463-537 (1972)

6) Calza L, Agnati LF, Fuxe K, Giardino L and Goldstein M: Morphometrical analysis of the distribution of luteinizing hormone-releasing hormone and tyrosine hydroxylase-immunoreactive nerve terminals within the lateral palisade zone of the median eminence of the male rat. Neurosci Lett, 43: 179-183 (1983)

7) Ibata Y, Watanabe K, Kinoshita H, Kubo S, Sano Y, Sin S, Hashimura E and Imagawa K: Detection of catecholamines and luteinizing hormone-releasing hormone (LH-RH) containing nerve endings in the median eminence and the organum vasculosum laminae terminalis by fluorescence histochemistry and immunohistochemistry on the same microscopic sections. Neurosci Lett, 11: 181-186 (1979)

8) McNeil TH, Scott DE and Sladek JR, Jr: Simultaneous monoamine histofluorescence and neuropeptide immunocytochemistry: Localizations of catecholamines and luteinizing hormone-releasing hormone in median eminence. Peptides, 1: 59-68 (1981)

9) Hoffman GE, Wray S and Goldstein M: Relationship of catecholamines and LHRH: Light microscopic study. Brain Res Bull, 9: 417-430 (1982)

10) Hoffman GE: Organization of LHRH cells: Differential apposition of neurotensin, substance $P$ and catecholamine axons. Peptides, 6: 439-461 (1985)

11) Jennes L, Beckman WC, Stumpf WE and Grzanna R: Anatomical relationships of serotoninergic and noradrenalinergic projections with the GnRH system in the septum and hypothalamus. Exp Brain Res, 46, 331-338 (1982)

12) Jennes L, Stumpf WE and Tappaz ML: Anatomical relationships of dopaminergic and GABAergic systems with the GnRH-systems in the septo-hypothalamic area. Exp Brain Res, 50: 91-99 (1983)

13) Lehman MN, Karsch FJ and Silverman AJ: Potential sites of interaction between catecholamines and LHRH in the sheep brain. Brain Res Bull, 20: 49-58 (1988)

14) Watanabe $T$ and Nakai $Y$ : Electron microscopic cytochemistry of catecholaminergic innervation of LHRH neurons in the medial preoptic area of the rat. Arch Histol Jpn, 50: 103-112 (1987)

15) Leranth C, MacLusky NJ, Shanabrough $\mathbf{M}$ and Naftolin F: Catecholaminergic innervation of luteinizing hormone releasing hormone and glutamic acid decarboxylase immunopositive neurons in the rat medial preoptic area. Neuroendocrinology, 48: 591-602 (1988)

16) Hökfelt $T$, Fuxe $K$ and Goldstein $M$ : Immunohistochemical studies on monoamine-containing cell systems. Brain Res, 62: 461-469 (1973)

17) Ajika K: Simultaneous localization of LHRH and catecholamines in rat hypothalamus. J Anat, 128: 331-347 (1979)

18) Kiss $\mathbf{J}$ and Halász B: Demonstration of serotoninergic axons terminating on luteinizing hormonereleasing hormone neurons in the preoptic area of the rat using a combination of immunocytochemistry and high resolution autoradiography. Neuroscience, 14: 69-78 (1985)

19) Leranth C, MacLusky NJ, Sakamoto H, Shanabrough $M$ and Naftolin F: Glutamic acid decarboxylase-containing axons synapse on LHRH neurons in the rat medial preoptic area. Neuroendocrinology, 40: 536-539 (1985)

20) Leranth C, MacLusky NJ, Shanabrough $\mathbf{M}$ and Naftolin F: Immunohistochemical evidence for synaptic connections between pro-opiomelanocortin-immunoreactive axons and LHRH-neurons in the preoptic area of the rat. Brain Res, 449: 167-176 (1988)

21) Chen WP, Witkin JW and Silverman AJ: Beta-endorphin and gonadotropin-releasing hormone 
synaptic input to gonadotropin-releasing hormone neurosecretory cells in the male rat. J Comp Neurol, 286: 85-95 (1989)

22) Norgren $\mathrm{RB}, \mathrm{Jr}$ and Lehman $\mathrm{MN}$ : A double-label pre-embedding immunoperoxidase technique for electron microscopy using diaminobenzidine and tetramethylbenzidine as markers. J Histochem Cytochem, 37: 1283-1289 (1989)

23) Wray S and Hoffman G: Catecholamine innervation of LH-RH neurons: a developmental study. Brain Res, 399: 327-331 (1986)

24) Day TA, Blessing W and Willoughby JO: Noradrenergic and dopaminergic projections to the medial preoptic area of the rat. A combined horseradish peroxidase/catecholamine fluorescence study. Brain Res Bull, 193: 543-548 (1980)

25) Howe PRC, Costa M, Furness JB and Chalmers JP: Simultaneous demonstration of phenylethanolamine-N-methyl transferase immunofluorescent and cathecholamine fluorescent nerve cell bodies in the rat medulla oblongata. Neuroscience, 5: 2229-2238 (1980)

26) King JC and Anthony ELP: LHRH neurons and their projections in human and other mammals: species comparisons. Peptides, 5: 195-207 (1984)

27) De Paolo LV, King RA and Carrillo AJ: In vivo and in vitro examination of an autoregulatory mechanism for luteinizing hormone-releasing hormone. Endocrinology, 120: 272-279 (1987)

[Received February 14, 1990: Accepted March 17, 1990] 